Biotechnology Research

http:/www.journals.zu.edu.eg/journalDisplay.aspx?Journalld=1\&queryType=Master

\title{
EFFECT OF HEPATOPROTECTIVE ROLE EVALUATION OF Hibiscus rosa-sinensis LEAVES AND POMEGRANATE (Punica granatum) PEELS AQ UEOUS EXTRACTS ON MALE ALBINO RATS
}

\author{
Mahmoud Sh.S. El-Sayed*
}

Agric. Biochem. Dept., Fac. Agric., Ain Shams Univ., PO. Box 68, Hadayek, Shubra 11241, Cairo, Egypt

\section{Received: 25/07/2017; Accepted: 17/09/2018}

\begin{abstract}
The current study sought to investigate the influence of individual and combined in different levels of natural products (aqueous extract of Hibiscus rosa-sinensis leaves-AEHRS, aqueous extract of pomegranate (punica granatum) peels-AEPP- and mixture of both) in order to assess the potency of the previous aqueous natural products extracts against liver diseases (oxidative stress). The serum aspartate aminotransferase (AST); alanine aminotransferase (ALT); alkaline phosphatase (ALP) and total bilirubin were assayed after 7, 14 and 21 days. Male albino rats were used in this study which contained twelve groups, six animals each. Group (I) normal control without any extract of AEHRS leaves or AEPP. Group (II) injected with carbon tetrachloride $\left(\mathrm{CCl}_{4}\right)$ induced oxidative stress in rats $\left(\mathrm{CCl}_{4}\right.$ control-treated group).Groups (III)leaves extract $250 \mathrm{mg} / \mathrm{kg}$ b.wt. of HRS, (IV) leaves extract $500 \mathrm{mg} / \mathrm{kg}$ b.wt. of HRS, (V) leaves extract $750 \mathrm{mg} / \mathrm{kg}$ b.wt. of HRS, (VI) peels extract $100 \mathrm{mg} / \mathrm{kg}$ b.wt. of P.granatum, (VII) peels extract $200 \mathrm{mg} / \mathrm{kg}$ b.wt. of P.granatum, (VIII) peels extract $300 \mathrm{mg} / \mathrm{kg}$ b.wt. of P.granatum, (IX) AEHRS leaves and AEPP mixture 125/125 $\mathrm{mg} / \mathrm{kg}$ b.wt. (X) AEHRS leaves and AEPP mixture 225/225 mg/kg b.wt, (XI) AEHRS leaves and AEPP mixture $350 / 350 \mathrm{mg} / \mathrm{kg}$ b.wt .In addition, one group for carbon tetrachloride rats group which treated with AEHRS leaves and AEPP mixture 400/400 mg/kg b.wt (XII), respectively. All groups were received the extracts daily oral except for normal control group (I). The present data demonstrate that AEHRS leaves, AEPP and their mixtures significantly attenuated liver functions parameters in serum when comparing with normal control group (I) and intoxicated control group (II). These findings suggest that AEHRS leaves, AEPP and mixtures of both have a potent hepatoprotective effect, where ALT, AST, ALP and total bilirubin decreased from $29.55 \pm 1.15$ to $20.15 \pm 0.87 \mathrm{U} / 1$, from $47.97 \pm 1.66$ to $30.99 \pm 1.78 \mathrm{U} / 1$, from $305.96 \pm 35.61$ to $170.55 \pm 46.42 \mathrm{U} / 1$ and from $3.11 \pm 0.02$ to $2.21 \pm$ $0.81 \mathrm{mg} / \mathrm{dl}$ respectively.
\end{abstract}

Key words: Liver function parameters, aqueous extracts, Hibiscus rosa-sinensis leaves, pomegranate (punica granatum) peels, hepatoprotective role.

\section{INTRODUCTION}

The plant phenolic compounds play an important role in the protection of several disorders. Some of plant derived compounds possess potent hepatoprotective efficacy.

HRS possess multiple biological activities including antioxidant, antispermatogenic, androgenic, antitumor and anticonvulsant suggesting the hepatoprotective effect of HRS may be due its antioxidant activity (Nidih $\boldsymbol{e t}$ al., 2009).

* Corresponding author: Tel. : +205522610222 E-mail address:
The leaves of Hibiscus rosa-sinensis, a wellknown member of the family Malvaceae, were found to contain large amounts of phenolic and flavonoid compounds. Methanolic extract of Hibiscus rosa-sinensis possessed significant antioxidant activity as compared to aqueous extract (Garg et al., 2012). The efficacy of Hibiscus rosa-sinensis leaf extract in relieving the hepatic oxidative stress associated with streptozotocin (STZ) induced diabetic rat model was investigated by Zaki et al. (2017). The effect of oral administration of aqueous methalonic extract of Hibiscus rosa-sinensis 
leaves $(400 \mathrm{mg} / \mathrm{kg}$ ) on streptozotocin (STZ) induced diabetic rats and alteration in liver and kidney functions. The treatment of diabetic rats with hibiscus leaves extract reduced levels of plasma aspartate aminotransferase (AST) and alanine aminotransferase (ALT). Hibiscus rosasinensis could have great importance as a safe therapeutic agent. Hibiscus leaves extract has a significant hypoglycemic and hypocholestrolemic effects in diabetic rats which may led to a decrease in oxidative stress and improvement of liver functions.

The hepatoprotective effects of Hibiscus rosa-sinensis flower extract demonstrated that the lipid lowering action of this natural product may be mediated through inhibition of hepatic cholesterol biosynthesis, increased fecal bile acids excretion and enhanced plasma lecithin: cholesterol acyl transferase activity and reduction of lipid absorption in the intestine. Liver protective plant contains a variety of chemical constituents like phenols, coumarins, glycosides, alkaloids, tannins and flavonoids (Yazdanparast and Bahramika, 2006; Pengelly, 2004).

A possible mechanism of the Hibiscus rosasinensis flower extracts as hepatoprotective may be due to its antioxidant effect or inhibition of cytochrome $\mathrm{P}_{450}$. This might be due to the higher contents of flavonoids presents in the extract, which could have reduced the accumulation of unwanted hypercholesterolemia derived metabolites. Dietary intake of HRS flower extract can be beneficial to patients suffering from hypercholesterolemia and liver diseases. Hepatoprotective plant species, seeking vast multidimensional future research work up to the molecular level to establish new up to date scientific data about this plant species and to elucidate its exact mechanism of protective effect (Biswas et al., 2014).

Certain flavonoids, steroids have protective effect on liver due to its antioxidant properties. Phytochemically flavonoids and alkaloids might play role in hepatoprotective activity. Phenolic compounds and flavonoids have pharmacological properties such as antioxidant, antimutagenic, antithrombotic, anti-inflammatory, anticancer and antihyperlipidemic. The flavonoids are well documented as hepatoprotective activities. Hence it has been reported to be effective in liver diseases.
Hibiscus rosa extract significantly reduced the elevated activities of serum AST, ALT indicating that this attenuation effects of HRE could be attributed to its phytochemical phenolics, predominantly flavonoids, triterpenes and tannins. It has been demonstrated that these compounds reduce the risk of hepatotoxicity by acting against free radical mediated damages to restore the functional integrity of the hepatocytes membrane, it is also consequently improved the liver from $\mathrm{CCl}_{4}$-induced injury (Yin et al., 2011). On the same line, Fu et al. (2008) demonstrated that a polyphenolic antioxidant, curcumin, significantly protects the liver from CCl4-induced injury by reducing the elevated activities of serum ALT and AST.

Hibiscus rosa sinensis extract post-treatment (100 mg/kg b.w., orally/day, for 4 weeks) for rats, whose of liver injuries, significantly reduced the all alternations of liver functions, antioxidant defenses anoxidative stress-markers with time dependent manner. It was clear that both $\mathrm{CCl}_{4}$-induced alternation and Hibiscus rosa sinensis extract amelioration effects were of hepatotoxic stage-dependence. So, it is suggested that, Hibiscus rosa sinensis extract effectively ameliorated the changes observed with $\mathrm{CCl}_{4}$ injuries in liver, possibly through antioxidant and/or free radical scavenging effects of its phenolic compounds, specially flavonoids, triterpenes and tannins, which previously were demonstrated as a phytochemical components in this extract as mentioned by Mubarak et al. (2016).

The protective effects of the methanolic extract of Hibiscus rosa sinensis could be due to the presence of polyphenolic content. Quercetin being one of its major components therefore the protective effect may be attributed on the quercetin as well as its synergistic effect with other polyphenols. The results indicated the antioxidant properties of HRS extract against thioacetamide (TAA) induced biochemical alterations which recorded by Nafees et $\boldsymbol{a l}$. (2013).

Protective effect of Hibiscus rosa sinensis extract on serum AST and ALT level was observed. Significant change in these parameters was found in thioacetamide (TAA) treated groups as compared to control group $(\mathrm{P}<0.001)$. Pretreatment with HRS was found significantly effective at lower dose $(100 \mathrm{mg} / \mathrm{kg}$ b.wt.) AST 
$(\mathrm{P}<0.01)$ and ALT $(\mathrm{P}<0.001)$ and at higher dose $(200 \mathrm{mg} / \mathrm{kg}$ b.wt.), AST $(\mathrm{P}<0.001)$, ALT $(\mathrm{P}<0.001)$ in the normalization of these markers when compared to TAA treated group.

The biochemical and histopathological findings showed that HRS can distinctly reduce hepatic injury induced by TAA administration in experimental rats.

HRS possess hepatoprotective and antioxidant action on TAA induced liver toxicity in rats. The hepatoprotective effect of it may be due to its ability to block the bioactivation of thioacetamide and by scavenging the free radicals and inhibition of lipid peroxidation. TAA administration caused oxidative stress in the liver. Pretreatment of HRS stabilize that stress in the liver. Further work is however needed to define the exact mechanisms which will explain the hepatoprotective action of HRS. (Nafees et al., 2013).

The extract of hibiscus leaves significantly inhibited the increase in the activities of AST and ALT in diabetic rats and it reduced the pathology of the liver (Zaki et al., 2017).

Pomegranate (Punica granatum L.), belongs to punicaceae family. Flavonoid-rich polyphenol fractions from pomegranate inducing chemicals with a potentially lower toxicology profile than other therapies. All parts of this plant were used to treat various ailments. The extract of root bark has been reported to exert some sugar lowering action in animals (Carraz et al., 1978), the extract of stem bark is used as antihelmintic, green leaves are made as a paste and applied in conjunctivitis (Satyavati et al., 1978), flowers used as antihelmintic, (Singhal, 1983), as hypoglycaemic agent (Jafri et al., 2000), peels displayed, haemostatic, antidiarrhoeal antifertility, adjunctive periodontal (Sastravaha et al., 2003), as an antifungal agent against candidosis associated with denture stomatitis (Vasconcelos et al., 2003), as a strong therapy for leukemia cells (Kawaii and Lansky, 2004), seed extract showed antidiarrhoeal activity (Das et al., 1999), seed displayed hypoglycaemic activity (Das et al., 2001) and fruit extract possesses antioxidant activity (Noda $\boldsymbol{e t} \boldsymbol{a l} ., 2002$ ), improves a depressive state and bone properties in menopausal syndrome model (Mori-Okamoto et al., 2004), reduced common carotid intimaemedia thickness, blood pressure and LDL oxidation (Aviram et al., 2004) and inhibit skin tumorigenesis in mice (Afaq et al., 2004).

Pomegranate juice contains, a wide of polyphenolic compounds including ellagic, gallic, anthocyanins and tannins especially punicalagin, which is a power antioxidant, pomegranate showed antioxidant activity three times higher than those of green tea (Schubert et al., 1999).

The Pomegranate rind contains tannins, anthocynins, flavonoids, pectins (Nozire and Serpil, 1993), ellagitannins (punicalin, punicalagin, granatin, gallagyldilactone, casurinin), pedunculagin, tellimagrandin, corilagin (Satomi et al., 1993), ellagic tannins, gallic, ellagic acids, ursolic acid (Ben-Nasr et al., 1996) and catechin (Chidambara et al., 2004) three estrogen compounds luteolin, quercetin and kaempferol (Van-Elswijk et al., 2004).

Pomegranate is known to contain estrogens (estradiol, estrone, estriol) and shows estrogenic activities in mice (Mori-Okamoto et al., 2004) the repeated overdose administration of pomegranate extract pericarps for month in male albino rats led to significant increase in (AST), (ALT) and (ALP).

Pharmacological properties of pomegranate extracts have been scrutinized, with antimicrobial, anti-parasitic, anti-viral, and anticancer effects were noted by Kim et al. (2002). The fermented juice is potently antioxidant and oil polyphenols inhibit eicosanoid enzymes cyclooxygenase and lipoxygenase (Schubert et al., 1999). An extract of the flowers lowers blood sugar in rodents (Jafri et al., 2000) and the fresh juice inhibits LDL oxidation and atheromatous plaque formation in rodents and humans (Aviram et al., 2000). The juice contains flavonoids including anthocyanins and phenolic acids, and the pericarps tannins and ellagitannins (Ben Nasr et al., 1996). Flavonoids and tannins inhibit cancer cell grown in vitro and in vivo, while the class of $18 \mathrm{C}$ trans fatty acids known as conjugated linoleic acid (CLA), structurally related to punicic acid, possess cancer arrestive properties (Igarashi and Miyazawa, 2000) and (Caltagirone et al., 2000).

$P$. granatum can provide a definite protective effect against chronic hepatic injury caused by $\mathrm{CCl}_{4}$ in rats, which may mainly be associated with anti-oxidative effects. 
Levels of the serum marker enzymes of hepatic damage, ALT, AST, ALP and total bilirubin increased significantly in $\mathrm{CCl}_{4}$ treated rats compared to the control group. In contrast, $P$. granatum at $2 \mathrm{ml} / \mathrm{rat}$ prevented the liver damage as judged by the decreased enzyme levels as compared to $\mathrm{CCl}_{4}$ - induced liver damage (ALT; 71.63\%, AST; 35.96\%, ALP; $19.23 \%$ and TB; $16.09 \%$, respectively). In addition, pomegranate administration alone caused insignificant change in all liver function enzymes except for ALP where it was diminished significantly $(-34.6 \%, \mathrm{P}<0.05)$. The increased levels of these enzymes (ALT, AST and ALP) were significantly decreased by treatment with $P$. granatum juice, implying that the juice prevented the liver damage which was further confirmed by the reduced amount of histopathological injuries (El-Khadragy, 2011) the hepatoprotective effects of $P$. granatum are presented through multiple ways. $P$. granatum scavenges free radicals that produced by $\mathrm{CCl}_{4}$ and by increases the activity of antioxidantdefense system. These actions of $P$. granatum are of significant clinical importance, as abuse of alcohol or other xenobiotics damages the liver in a manner similar to this $\mathrm{CCl}_{4}$ intoxication model. Further studies with the individual antioxidant compounds isolated from $P$. granatum root extract on hepatocytes are underway which will enable us to understand the exact mechanism of hepatoprotective action by P. granatum.

The present study aims to investigate the effect of Hibiscus rosa-sinensis aqueous leaves extract, pomegranate (Punica granatum L.) peels aqueous extract and mixture of both on liver functions in rats to evaluate hepatoprotective role of punica granatum and hibiscus.

\section{MATERIALS AND METHODS}

\section{Plant Material Collection}

The leaves of Hibiscus rosa sinensis were collected from Faculty of Agriculture, Ain Shams University garden, Egypt while the fruits of pomegranate (Punica granatum) were purchased from local market. All plant materials were identified and authenticated by Horticulture department, Faculty of Agriculture, Ain Shams University. The samples were washed with distilled water to remove any impurities and dried under shade. Then the dried plant materials were ground into powder with grinder mixture.

\section{Extract Preparation}

Boiled distilled water $(500 \mathrm{ml})$ were added to $8 \mathrm{~g}$ dry powder pomegranate peels and the same conditions with $8 \mathrm{~g}$ powder Hibiscus rosa sinensis, then left for 10 minutes and filtered. The filtrates were dried at $40-45^{\circ} \mathrm{C}$. The yields of powder residue were $5 \mathrm{~g}$ of punica granatum and $4 \mathrm{~g}$ of hibiscus rosa sinensis

\section{Animals \\ Male albino rats weighting $120 \pm 10 \mathrm{~g}$ were obtained from experimental farmland animals unit, Ministry of Health, Helwan, Cairo, Egypt. The animals were caged and provided with food and water ad-libitum. The rats were kept for one week to adapt to the laboratory conditions before starting of the experiment. The number of rats (72) adult male albino rats were divided into twelve groups (6 rats/ each).}

\section{Experimental Design}

Three dose levels of each AEHRS, AEPP beside their mixture at four doses three for normal animals $(125 / 125,225 / 225 /, 350 / 350)$ and one for carbon tetrachloride rats which treated with a mixture of (AEHRS leaves) and (AEPP) at dose of $400 / 400 \mathrm{mg} / \mathrm{kg}$ body weight. In the experimental rats were divided into the following groups.

Group I: normal control rats.

Group II: rats were injected with carbon tetrachloride $(0.1 \mathrm{ml} / 100 \mathrm{~g}$ body weight, twice a week, subcutaneously).

Group III: normal rats daily received AEHRS leaves ( $250 \mathrm{mg} / \mathrm{kg}$ b.wt.) for 21 days.

Group IV: normal rats daily received AEHRS leaves $(500 \mathrm{mg} / \mathrm{kg}$ b.wt.) for 21 days.

Group V: normal rats daily received AEHRS leaves (750 mg/kg b.wt.) for 21 days.

Group VI: normal rats daily received AEPP (100 $\mathrm{mg} / \mathrm{kg} \mathrm{b.wt}$.) for 21 days.

Group VII: normal rats daily received AEPP ( $200 \mathrm{mg} / \mathrm{kg}$ b.wt.) for 21 days.

Group VIII: normal rats daily received AEPP (300 mg/kg b.wt.) for 21 days. 
Group IX: normal rats daily received AEHRS leaves and AEPP mixture $(125 / 125 \mathrm{mg} /$ kg b.wt.) for 21 days.

Group X: normal rats daily received AEHRS leaves and AEPP mixture $(225 / 225 \mathrm{mg} /$ kg b.wt.) for 21 days.

Group XI: normal rats daily received AEHRS leaves and AEPP mixture (350/350 $\mathrm{mg} / \mathrm{kg}$ b.wt.) for 21 days.

Group XII: carbon tetrachloride rats daily received AEHRS leaves and AEPP mixture (400/400 mg/kg b.wt.) for 21 days.

\section{Collection of Blood}

The blood was withdrawn from the retroorbital sinus puncture of the eye using mild ether anesthesia. At 7 days, 14 days and 21 days the collected samples were centrifuged for 10 min. (Jadeja et al., 2009). Serum alanine aminotransferase (ALT), aspartate aminotransferase (AST) were estimated according to Reitman and Frankel (1957) method, whereas alkaline phosphatase (ALP) activity was estimated by Belfield and Goldberg (1971) method. Also, Total bilirubin (TB) of serum was assayed according to the method of Schmidt and Eisenburg (1975).

\section{Chemical and Equipments}

All chemicals and equipments used were of analytical grade and purchased from ElGomhoria Chemicals Co and electoscient chemicals Co.

\section{Statistical Analysis}

All the data were expressed as mean \pm SE. Statistical analysis was carried out using student's t-test to analyze the significance between the groups. A value of $\mathrm{P}<0.05$ was considered to be significant (Sendecor and Cochran, 1969).

\section{RESULTS AND DISCUSSION}

Activities of serum alanine aminotransferase (ALT) is the hepatic marker enzyme and more specific to liver and thus is a better parameter of detecting liver injury. It is estimated in serum of male albino rats received different levels of natural products (AEHRS leaves and AEPP) which were illustrated in Table 1 and Fig. 1. Results obtained in this study indicated that different doses of natural products (AEHRS leaves and AEPP) either in a single or combined doses showed marked decrease in enzyme activity after 7 days in rat's serum of all groups comparing with normal contorl (I), $\mathrm{CCl}_{4}$ control (II) and the last group (XII). This finding are reported with Zari and Al-Attar (2011) who found that the protective effect of pomegranate peel extracts in recovering the induced reduction in hepatic function in the current study is indicated by the significant reduction in ALT activities. In addition, El-Sayed $\boldsymbol{e t}$ al. (2014) on their study obtained that the 15 days pre and 15 days co-administration of pomegranate peel extracts with oxytetracycline caused a significant reduction in the activities of ALT compared with oxytetracycline-treated group. On the other hand, this former decrease is coincided with Biswas et al. (2014) who found that feeding rats on Hibiscus rosa-sinensis flower extract 240 $\mathrm{mg} / \mathrm{kg}$ b.wt., was more effective on decreasing the elevated of liver enzyme ALT due to hyperlipidemia. Also, this former decrease was not continued until 14 days in all groups when compared to normal control only but in some groups was continued and other was not but higher than normal control only like group (V) which received high dose of AEHRS leaves and group (VII) which given medium dose of AEPP, besides group (XI) which given mixture of both natural products with dose $(125 / 125 \mathrm{mg} / \mathrm{kg}$ b.wt.). These results indicated that high dose of AEHRS leaves after 14 days individualy or combined with AEPP resulted in higher ALT activity compared to normal control only and this finding was along with medium dose of AEPP $200 \mathrm{mg} / \mathrm{kg}$ b.wt. However, respecting to enzyme activity of ALT after 21 days, was significantly decreased in single or mixture groups comparing with (I, II and XII groups) except group (III) which had received low dose of AEHRS leaves and groups (X and XI) which given mixture doses $(225 / 225 \mathrm{mg} / \mathrm{kg}$ b.wt, $350 / 350$ $\mathrm{mg} / \mathrm{kg}$ b.wt.) enzyme activity was not changed significantly comparing to normal control only. Generally, it could be noticed that higher or medium doses of AEHRS leaves or all doses AEPP individual induced lower serum ALT activity when compared to $\mathrm{CCl}_{4}$ control (II) and the last group (XII) which illustrated in Table 1 
Table 1. Effect of different concentrations of natural products (Aqueous extract of Hibiscus rosa-sinensis leaves-(AEHRS)-, aqueous extract of pomegranate (punica granatum) peels -(AEPP)- and their mixture) on serum alanine-amino transferase ALT activity (U/L) in male albino rats

\begin{tabular}{|c|c|c|c|c|c|c|c|c|c|c|c|c|}
\hline \multirow{2}{*}{$\begin{array}{l}\text { Treatments } \\
\text { Days }\end{array}$} & \multirow{2}{*}{$\begin{array}{l}\text { Normal } \\
\text { Control }\end{array}$} & \multirow{2}{*}{$\begin{array}{c}\mathrm{CCl}_{4} \\
\text { Control }\end{array}$} & \multicolumn{3}{|c|}{ AEHRS leaves (mg/kg b.wt.) } & \multicolumn{3}{|c|}{$\operatorname{AEPP}(\mathrm{mg} / \mathrm{kg}$ b.wt) } & \multicolumn{4}{|c|}{ AEHRS leaves and AEPP mixture (mg/kg b.wt) } \\
\hline & & & 250 & 500 & 750 & 100 & 200 & 300 & $125 / 125$ & $225 / 225$ & $350 / 350$ & $\begin{array}{c}\mathrm{CCl}_{4} \text { rats }+ \\
400 / 400\end{array}$ \\
\hline 7 & $28.60 \pm 0.91$ & $60.33 \pm 1.07$ & $21.41 \pm 2.66$ & $23.43 \pm 3.19$ & $22.88 \pm 2.07$ & $18.89 \pm 1.22 *$ & $22.37 \pm 3.04$ & $20.55 \pm 1.57^{*}$ & $18.90 \pm 1.55^{*}$ & $23.77 \pm 2.11$ & $22.06 \pm 3.58$ & $47.00 \pm 3.73$ \\
\hline 14 & $26.37 \pm 0.77$ & $64.55 \pm 1.93$ & $19.33 \pm 0.66$ & $25.77 \pm 1.69$ & $30.71 \pm 1.45$ & $17.99 \pm 0.92$ & $28.66 \pm 2.19$ & $22.77 \pm 1.03$ & $27.99 \pm 1.76$ & $21.33 \pm 0.95$ & $20.51 \pm 1.92$ & $50.10 \pm 2.90$ \\
\hline 21 & $29.55 \pm 1.15$ & $69.77 \pm 2.95$ & $29.91 \pm 0.52$ & $23.87 \pm 0.48^{*}$ & $21.65 \pm 1 *$ & $22.26 \pm 0.33 *$ & $20.15 \pm 0.87 *$ & $24.88 \pm 1.19$ & $23.22 \pm 1.02 *$ & $29.91 \pm 1.06$ & $29.93 \pm 1.14$ & $53.90 \pm 2.11$ \\
\hline
\end{tabular}

Values are expressed as mean \pm SE. $n=6$

Significant difference $(\mathrm{P}<0.05)$ compared with normal control and $\mathrm{CCl}_{4}$ control groups

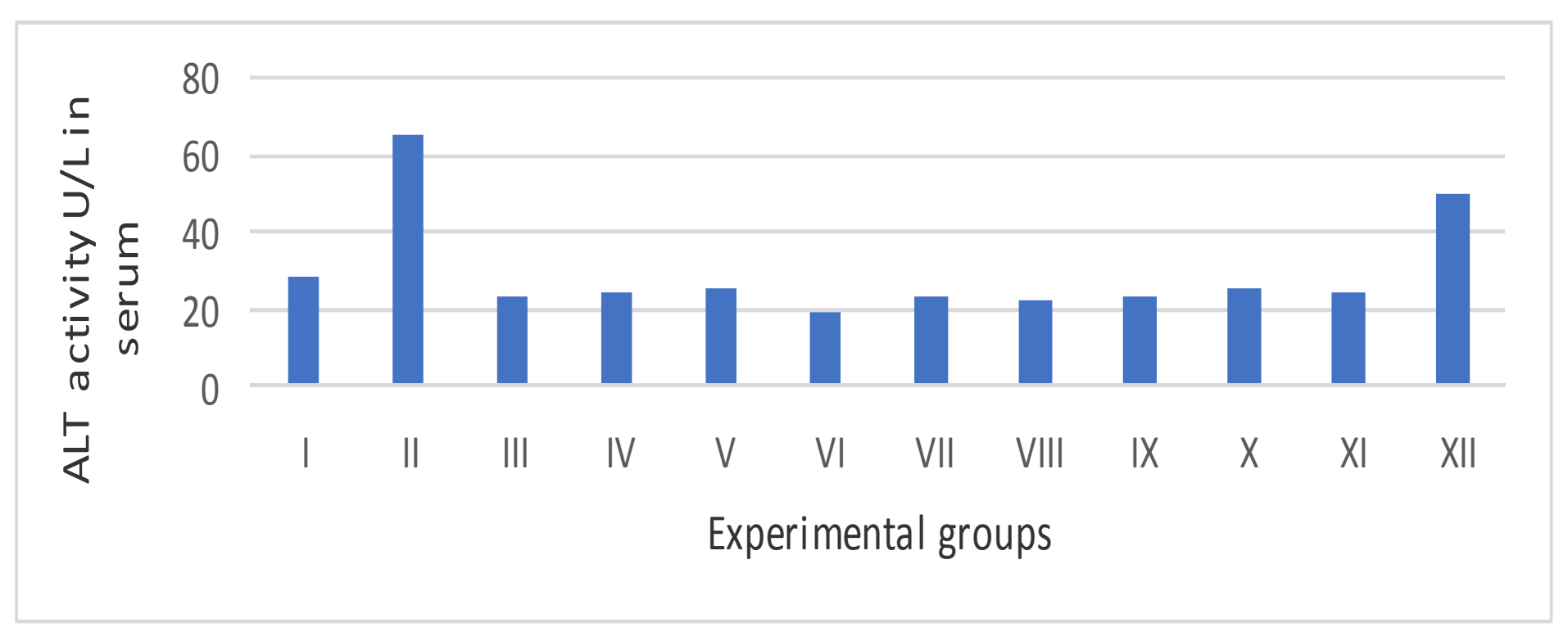

Fig. 1. Effect of different concentrations of natural products (Aqueous extract of Hibiscus rosa-sinensis leaves-(AEHRS)-, aqueous extract of pomegranate (punica granatum) peels -(AEPP)- and their mixture on serum alanine-amino transferase ALT activity (U/L) in male albino rats 
and Fig. 1. Meanwhile lower dose or higher doses of AEHRS leaves and AEPP in mixture induce lowering ALT activity when compared to (II, XII) groups.

Results represented in Table 2 and Fig. 2 showed activity of serum aspartateaminotransferase (AST-hepatic marker enzyme). The represented results illustrated that AST activity was slightly decreased in some groups after 7 days, and the others didn't exhibte appearance change comparing to normal control only. However, the AST activity after 14 days was decreased compared to normal control (I), $\mathrm{CCl}_{4}$ control (II) and the last group (XII). In relation to AST activity after 21 days it is pointed out that these activities were decreased slightly after this time compared to normal control only. While some groups such as AEHRS leaves (750 mg/kg b.wt.), AEPP (300 $\mathrm{mg} / \mathrm{kg}$ b.wt.) and the mixture of both AEHRS leaves and AEPP $(350 / 350 \mathrm{mg} / \mathrm{kg}$ b.wt.) revealed significant decrease in serum AST activity when compared to (I, II and XII) groups. It is pointed out that AST activity showed in all time a noticeable decrease. Also, the dose of AEHRS leaves and AEPP led to clear decrease in this activity at the end period of experiment, especially the high dose of AEHRS leaves and high dose of AEPP beside the high mixture dose of AEHRS and AEPP. That means that the extracts have a significant hepatoprotective activity. These results are in accordance with Saad et al. (2015) who mentioned that a significant decrease in AST activities in diabetic rats treated with punica granatum peel powder (PGPP) was observed. In addition Biswas et al. (2014) reported that the co-administration of Hibiscus rosa-sinensis flower extracts have prevented the increase serum AST. This is an agreement with the commonly accepted view that serum level of AST return to normal with healing of hepatic parenchyma and regeneration of hepatocytes.

Table 3 and Fig. 3 illustrated serum alkaline phosphatase activity (ALP activity) of rats received different doses of natural products aqueous extract of Hibiscus rosa sinensis leaves (AEHRS leaves) and aqueous extract of pomegranate peels (AEPP) beside mixtures of both. The represented results cleared that ALP activity after 7 days insignificantly decreased in all treated groups except in groups (V) which took high dose of AEHRS leaves and group (XI) also took the high dose of AEHRS leaves and AEPP mixture when compared to normal control only. Whereas, significant decrease in all treated groups was observed comparing with (II, XII) groups also, serum alkaline phosphate, showed reduction in its level after 14 days of experimental groups compared with normal control (I), $\mathrm{CCl}_{4}$ control (II) and the last group (XII). This lowering effect was attributed to individual level dose or combined dose of both AEHRS and AEPP, results revealed that the effect of dose level was cleared in serum ALP activity where cleared that the increasing of AEHRS leaves level induced lower ALP activity also, this reduction was shown in AEPP increasing dose comparing (I,II and XII) groups. However, the AEHRS leaves and AEPP combination revealed also lowering ALP activity in all treated groups comparing with (I, II and XII) groups. On the other hand, after 21 days of experiment lowest value was attributed to high dose of AEHRS which was $170.55 \mathrm{U} / \mathrm{L}$ compared to normal control $305.96 \mathrm{U} / \mathrm{L}, \mathrm{CCl}_{4}$ control 399.51 U/L and the last group 360.11 U/L. In addition, lowest value of ALP activity was also shown in AEPP groups which given high dose of AEPP which was $193.88 \mathrm{U} / \mathrm{L}$ compared to normal control $305.96 \mathrm{U} / \mathrm{L}, \mathrm{CCl}_{4}$ control $399.51 \mathrm{U} / \mathrm{L}$ and the last group 360.11 U/L. Also, the same decrease was recorded for mixture dose of AEHRS leaves and AEPP. On the other side, it is pointed out that ALP activity comparison between 14 and 21 days showed that ALP activity was increased except at high dose of AEHRS leaves it decreased from $210.91 \mathrm{U} / \mathrm{L}$ to $170.55 \mathrm{U} / \mathrm{L}$ and high dose of AEPP it decreased from $210.87 \mathrm{U} / \mathrm{L}$ to $193.88 \mathrm{U} / \mathrm{L}$. Also, it decreased at low level of AEPP where the values were $251.88 \mathrm{U} / \mathrm{L}$ and $226.17 \mathrm{U} / \mathrm{L}$. The decreasing in ALP activity attributed to AEPP is in agreement with Abdelmoneim et al. (2011) who found that pomegranate caused a significant reduction $(\mathrm{P}<0.05)$ in ALP activity when administrated in the form of juice or peel extracts. Also, Nwibo et al. (2016) found decreasing in ALP activity due to AEHRS leaves treatment on rats.

Mean values of serum total bilirubin were represented in Table 4 and Fig. 4. Results of serum total bilirubin demonstrated that this value was increase in normal control rats during time from $2.74 \mathrm{mg} / \mathrm{dl}$ to $2.98 \mathrm{mg} / \mathrm{dl}$ and $3.11 \mathrm{mg} / \mathrm{dl}$ 
Table 2. Effect of different concentrations of natural products (aqueous extract of Hibiscus rosa-sinensis leaves -AEHRS-, aqueous extract of pomegranate (punica granatum) peels -(AEPP)- and their mixture) on serum aspartate amino transferase AST (U/L) activity in male albino rats

\begin{tabular}{|c|c|c|c|c|c|c|c|c|c|c|c|c|}
\hline Treatments & \multirow{2}{*}{$\begin{array}{l}\text { Normal } \\
\text { Control }\end{array}$} & \multirow{2}{*}{$\underset{\text { Control }}{\mathrm{CCl}_{4}}$} & \multicolumn{3}{|c|}{ AEHRS leaves (mg/kg b.wt.) } & \multicolumn{3}{|c|}{$\operatorname{AEPP}(\mathrm{mg} / \mathrm{kg} \mathrm{b.wt.)}$} & \multicolumn{4}{|c|}{ AEHRS leaves and AEPP mixture (mg/kg b.wt.) } \\
\hline Days & & & 250 & 500 & 750 & 100 & 200 & 300 & $125 / 125$ & $225 / 225$ & $350 / 350$ & $\begin{array}{c}\mathrm{CCl}_{4} \text { rats }+ \\
400 / 400\end{array}$ \\
\hline 7 & $40.66 \pm 1.97$ & $67.23 \pm 1.77$ & $39.51 \pm 2.81$ & $38.26 \pm 2.40$ & $40.42 \pm 1.79$ & $40.11 \pm 1.67$ & $39.99 \pm 1.39$ & $33.04 \pm 1.69$ & $36.88 \pm 1.51$ & $37.71 \pm 2.51$ & $39.24 \pm 1.45$ & 55.71 \\
\hline 14 & $42.36 \pm 3.66$ & $69.78 \pm 2.13$ & $37.51 \pm 2.23$ & $40.91 \pm 2.51$ & $41.93 \pm 3.8$ & $39.77 \pm 3.49$ & $39.91 \pm 1.39$ & $41.69 \pm 2.88$ & $38.88 \pm 2.18$ & $30.61 \pm 1.45$ & $35.77 \pm 2.75$ & $57.00 \pm 3.13$ \\
\hline 21 & $47.97 \pm 1.66$ & $70.99 \pm 3.78$ & $45.91 \pm 2.04$ & $44.71 \pm 1.88$ & $30.99 \pm 1.78 *$ & $41.39 \pm 1.88$ & $39.71 \pm 1.96$ & $32.60 \pm 1.91 *$ & $45.19 \pm 1.56$ & $43.91 \pm 2.11$ & $38.99 \pm 2.90 *$ & $60.11 \pm 1.99$ \\
\hline
\end{tabular}

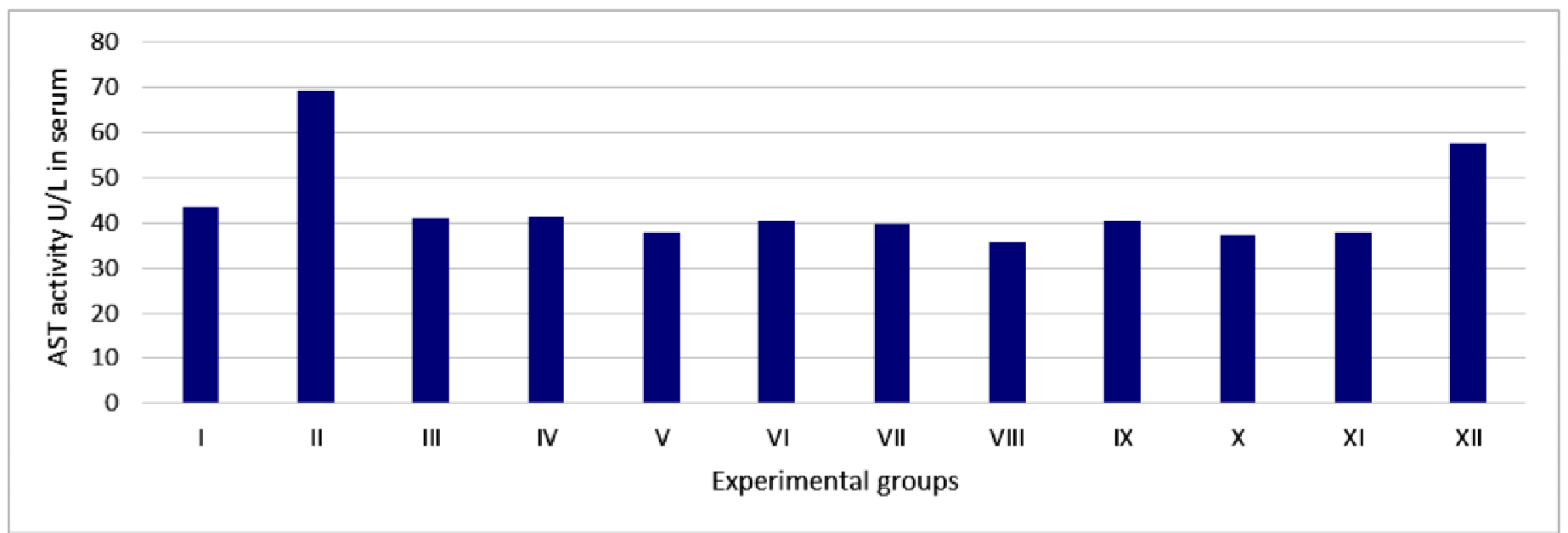

Fig. 2. Effect of different concentrations of natural products (aqueous extract of Hibiscus rosa-sinensis leaves -AEHRS -, aqueous extract of pomegranate (punica granatum) peels -(AEPP)- and their mixture) on serum aspartate amino transferase AST (U/L) activity in male albino rats 
Table 3. Effect of different concentrations of natural products (aqueous extract of Hibiscus rosa-sinensis leaves -AEHRS-, aqueous extract of pomegranate (punica granatum) peels -(AEPP-) and their mixture) on serum alkaline phosphatase (ALP) activity (U/L) in male albino rats

\begin{tabular}{|c|c|c|c|c|c|c|c|c|c|c|c|c|}
\hline \multirow{2}{*}{$\begin{array}{l}\text { Treatments } \\
\text { Days }\end{array}$} & \multirow{2}{*}{$\begin{array}{l}\text { Normal } \\
\text { Control }\end{array}$} & \multirow{2}{*}{$\begin{array}{c}\mathrm{CCl}_{4} \\
\text { Control }\end{array}$} & \multicolumn{3}{|c|}{ AEHRS leaves (mg/kg b.wt.) } & \multicolumn{3}{|c|}{$\operatorname{AEPP}(\mathrm{mg} / \mathrm{kg}$ b.wt.) } & \multicolumn{4}{|c|}{ AEHRS leaves and AEPP mixture (mg/kg b.wt.) } \\
\hline & & & 250 & 500 & 750 & 100 & 200 & 300 & $125 / 125$ & $225 / 225$ & $350 / 350$ & $\begin{array}{c}\mathrm{CCl}_{4} \text { rats }+ \\
400 / 400\end{array}$ \\
\hline
\end{tabular}

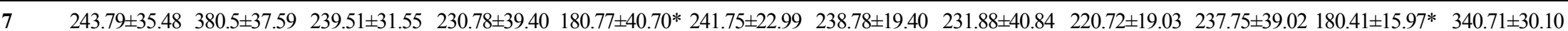

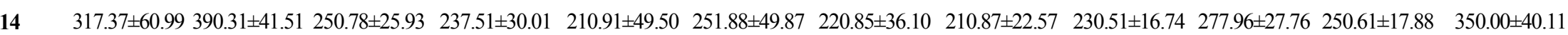

$21 \quad 305.96 \pm 35.61 \quad 399.51 \pm 50.13 \quad 301.67 \pm 50.21 \quad 260.71 \pm 32.15 \quad 170.55 \pm 46.42 * 226.17 \pm 51.91 \quad 290.91 \pm 48.99 \quad 193.88 \pm 19.37 * 240.99 \pm 39.71 \quad 290.17 \pm 44.75 \quad 260.51 \pm 49.29 \quad 360.11 \pm 50.99$

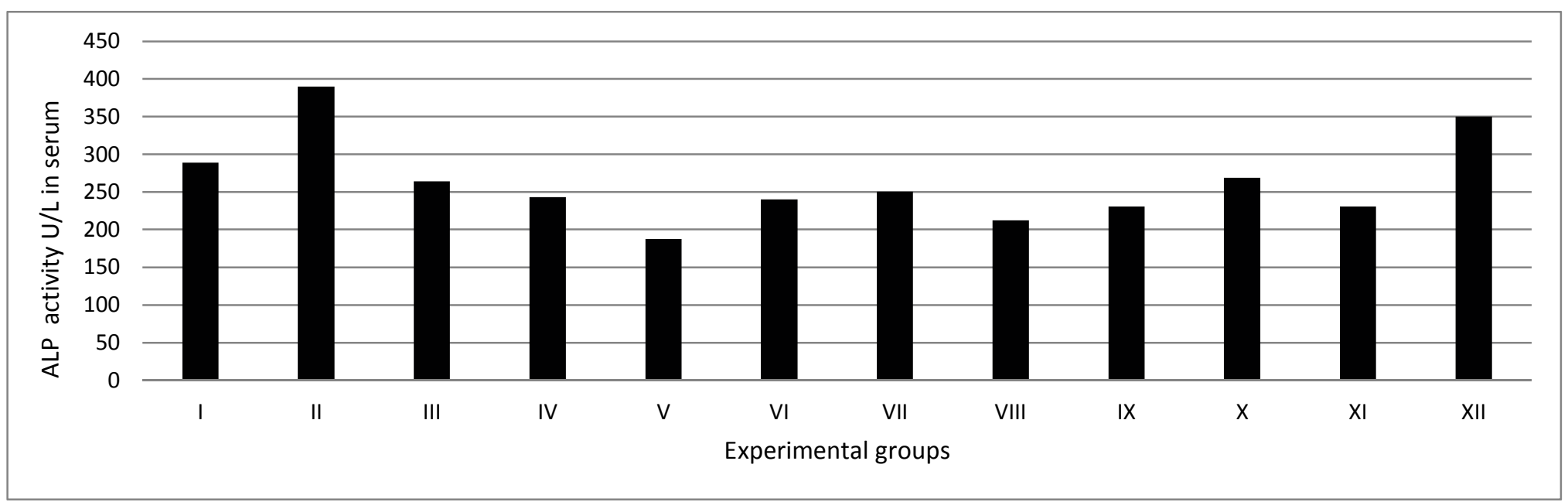

Fig. 3. Effect of different concentrations of natural products (aqueous extract of Hibiscus rosa-sinensis leaves -AEHRS-, aqueous extract of pomegranate (punica granatum) peels -(AEPP-) and their mixture) on serum alkaline phosphatase (ALP) activity (U/L) in male albino rats 
Table 4. Effect of different concentrations of natural products (aqueous extract of Hibiscus rosa-sinensis leaves -AEHRS, aqueous extract of pomegranate (punica granatum) peels -(AEPP)- and their mixture) on serum total bilirubin $(\mathrm{mg} / \mathrm{dl})$ in male albino rats

\begin{tabular}{|c|c|c|c|c|c|c|c|c|c|c|c|c|}
\hline \multirow{2}{*}{$\begin{array}{l}\text { Treatments } \\
\text { Days }\end{array}$} & \multirow{2}{*}{$\begin{array}{l}\text { Normal } \\
\text { Control }\end{array}$} & \multirow[t]{2}{*}{$\begin{array}{c}\mathrm{CCl}_{4} \\
\text { Control }\end{array}$} & \multicolumn{3}{|c|}{ AEHRS leaves (mg/kg b.wt.) } & \multicolumn{3}{|c|}{ AEPP (mg/kg b.wt.) } & \multicolumn{4}{|c|}{$\begin{array}{c}\text { AEHRS leaves and AEPP mixture (mg/kg } \\
\text { b.wt.) }\end{array}$} \\
\hline & & & 250 & 500 & 750 & 100 & 200 & 300 & $125 / 125$ & $225 / 225$ & $350 / 350$ & $\begin{array}{r}\mathrm{CCl}_{4} \text { rats }+ \\
400 / 400\end{array}$ \\
\hline 7 & $2.74 \pm 0.05$ & $4.81 \pm 0.09$ & $1.49 \pm 0.03$ & $2.21 \pm 0.22$ & $1.96 \pm 0.32$ & $1.53 \pm 0.38$ & $1.47 \pm 0.49$ & $2.31 \pm 0.61$ & $1.68 \pm 0.71$ & $2.15 \pm 0.31$ & $1.97 \pm 0.21$ & $3.11 \pm 0.13$ \\
\hline 14 & $2.98 \pm 0.15$ & $4.93 \pm 0.11$ & $2.6 \pm 0.05$ & $2.99 \pm 0.33$ & $2.38 \pm 0.27$ & $2.67 \pm 0.3$ & $2.71 \pm 0.2$ & $2.81 \pm 0.46$ & $2.95 \pm 0.06$ & $3.09 \pm 0.41 *$ & $3.02 \pm 0.56^{*}$ & $3.43 \pm 0.09$ \\
\hline
\end{tabular}

Values are expressed as mean \pm SE. $n=6 \quad$ Significant difference $(\mathrm{P}<0.05)$ compared with normal control and $\mathrm{CCl} \mathrm{C}_{4}$ control groups

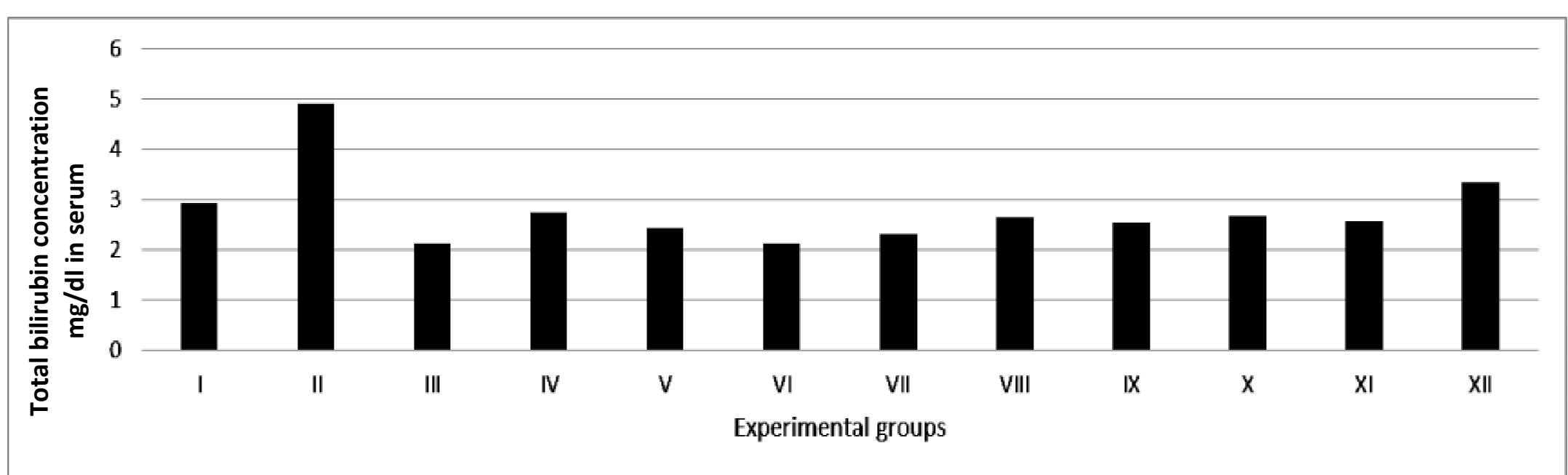

Fig. 4. Effect of different concentrations of natural products (aqueous extract of Hibiscus rosa-sinensis leaves -AEHRS, aqueous extract of pomegranate (punica granatum) peels -(AEPP-) and their mixture) on serum total bilirubin (mg/dl) in male albino rats 
through 7, 14 and 21 days, respectively. The same trend was observed in all groups under investigation through 7,14 and 21 days. But some groups revealed decreasing in this parameter after 21 days e.g. groups (III, VI, X and XI), which return to lower level after 21 days when compared to normal control (I), $\mathrm{CCl}_{4}$ control (II) and the last group (XII). It is obviously noticed that both AEHRS leaves and AEPP lowered serum total bilirubin level either alone or combined natural products in all treated groups compared with $\mathrm{CCl}_{4}$ control(II) and the last group(XII) except for group (X, XI) which showed markedly increase but return back to lower level after 21 days when compared to normal control (I) only. Entirely, it could be concluded that AEHRS leaves and AEPP significantly decreased serum total bilirubin in all doses and this lowering clearly appeared after 21 days comparing (I, II and XII) groups. Finally, both AEHRS leaves and AEPP have a decreasing effect on serum total bilirubin. These results are found by Abdelmoneim et al. (2011) they reported that pomegranate caused a significant reduction $(\mathrm{P}<0.05)$ in bilirubin when administrated in the form of juice or peel extracts.

In addition, Nwibo et al. (2016) reported that total bilirubin values were slightly lower when treated with hibiscus rosa sinensis leaves extracts. Slight reduction in bilirubin concentration is suggestive that the leaf products of HRS have potentials to impart processes leading to hemoglobin breakdown in the experimental rats.

\section{Conclusion}

Finally, according to the results presented above, the aqueous extract of hibiscus rosa sinensis (AEHRS leaves), aqueous extract of pomegranate peels (AEPP) and mixture of both possess hepatoprotective effect in rats. Which may involve lowering activities of sera ALT and AST, the diagnostic enzymes of liver functions.

\section{REFERENCES}

Abdelmoneim, A.G., M.A. Dkhil and S. Alquraishy (2011). Studies on the effect of pomegranate (Punica granatum) juice and peel on liver and kidney in adult male rats. J. Med. Pl. Res., 5 (20): 5083-5088.
Afaq, F., M. Saleem, C.G. Krueger, J.D. Reed and H. Mukhtar (2004). Antocyanin-and hydrolysable tannin-rich pomegranate fruit extract modulates MAPK and NF-kappa B pathways and inhibits skin tumorigenesis in CD-1 mice. Int. J. Cancer. 28.

Aviram, M., L. Dornfeld, M. Rosenblat, N. Volkova, M. Kaplan, R. Coleman, T. Hayek, D. Presser and B. Fuhrman (2000). Pomegranate juice consumption reduced oxidative stress, atherogenic modifications to LDL, and platelet aggregation: Studies in humans and in atherosclerotic apolipoprotein E-deficient mice. Ame. J. Clin. Nut., 71 : 1062 - 1076.

Aviram, M., M. Rosenblat, D. Gaitini, S. Nitecki, A. Hoffman, L. Dornfeld, N. Volkova, D. Presser, J. Attia, H. Liker and T. Hayek (2004). Pomegranate juice consumption for three years by patients with carotid artery stenosis ereduced common carotid intimamida thickniss, blood pressure and LdL oxidation. Clin. Nut., 23 (3): 423.

Belfield, A. and D.M. Goldberg (1971). Revised assay for serum phenyl phosphatase activity using 4-amino-antipyrine. Enzyme., 12 : 561573.

Ben-Nasr, C., N. Ayed and M. Metche (1996). Quantitative determination of the polyphenolic content of pomegranate peel. Z. Lebensm. Unters. Forsch., 203:374-378.

Biswas, A., U.J.A.D. Souza, S. Bhat and D. Damodar (2014). The hepatoprotective effect of Hibiscus rosa sinensis flower extract on diet induced Hypercholesterolemia in male albino wistar rats, int. J. Med. Pharm Sci., 4 (6): 1-10.

Caltagirone, S., C. Rossi, A. Poggi, F.O. Ranelletti, P.G. Natali, M. Brunetti, F.B. Aiello and M. Piantelli (2000). Flavonoids apigenin and quercetin inhibit melanoma growth and metastatic potential Int. J. Cancer, 87: 595-600.

Carraz, G.L.M., J. Willemot and P. Demenge (1978). Penta-O-gal-loyl- $\beta$-glucose is useful as an hypoglycaemic agent. Fr. Demande 2, 380.29 . 
Chidambara, M.K., V.K. Reddy, J.M. Veigas and U.D. Murthy (2004). Study on wound healing activity of Punica granatum peel. J. Med., 7(2): 256.

Das, A.K., S.C. Mandal, S.K. Banerjee, S. Sinha, B. Saha and M. Pal (1999). Studies on diarrhoeal activity of Punica granatum seed extract in rats. J. Ethnopharmacol., 15, 68 (1-3): 205.

Das, A.K., S.C. Mandal, S.K. Banerjee, S. Sinha, B. Saha and M. Pal (2001). Studies on the hypoglycaemic of Punica granatum seed in streptozotocin induced diabetic rats. Phytother. Res., 15: 628.

El-Khadragy, M.F. (2011). Hepatoprotective role of pomegranate (Punica granatum) Juice on carbontetrachloride-induced oxidative stress in rats. Afr. J. Biol. Sci., 7 (1): 135-149.

El-Sayed, A.S., A.M. Badawi and M.T. Asmaa (2014). The protective effect of olive leaf and pomegranate peel extracts on oxidative stress and liver injury induced by oxytetracycline in albino rats, J. Drug Res. Egypt, 35 (1): 3341.

Garg, D., A. Shaikh, A. Muley and T. Marar (2012). In vitro antioxidant activity and phytochemical analysis in extracts of Hibiscus rosa-sinensis stem and leaves. Free Radic. Antioxid., 2(3): 41-46.

Igarashi, M. and T. Miyazawa (2000). Newly recognized cytotoxic effect of conjugated trienoic fatty acids on cultured human tumor cells. Cancer Lett., 184: 173-179.

Jadeja, R.N., M.G. Thounaojam, V. Patel, R.V. Devkav and A.V. Ramachandran (2009). Anti hyperlipidemic potential of a polyherbal preparation on triton WR 1339 (Tyloxapol) induced hyper lipidemia: A comparison with lovastatin. Int. J. Green Pharm, (3) Suppl. (2): 119-124.

Jafri, M.A., M. Aslam, K. Javed and S. Singh (2000). Effect of Punica granatum Linn. (flower) on blood glucose level in normal and alloxan-induced diabetic rats. J. Ethnopharmacol., 70: 309-314.

Kawaii, S. and E.P. Lansky (2004). Differentiation-promoting activity of pomegranate (Punica granatum) fruit extracts in HI-60 humanpromyelocytic leukemia cells. J. Med. Food, 7(1): 13.

Kim, N.D., R. Mehta, W. Yu, I. Neeman, T. Livney, A. Amichay, D. Poirier, P. Nicholls, A. Kirby, W. Jiang, R. Mansel, C. Ramachandran, T. Rabi, B. Kaplan and E. Lansky (2002). Chemopreventive and adjuvant therapeutic potential of pomegranate (Punica granatum) for human breast cancer. Breast Cancer Res. Treat., 71: 203-217.

Mori-Okamoto, J., Y. Otawara-Hamamoto, H. Yamato and H. Yoshimura (2004). Pomegranate extract improves a depressive state and bone properties in menopausal syndrome model ovarienctomized mice. J. Ethnopharmacol., 92(1): 93.

Mubarak, O.E., N.F. Morsi and M. Hmama (2016). Roles of H. rosa sinensis extract in the treatment of liver against $\mathrm{CCL}_{4}$-induced hepatic oxidative stress and antioxidants disorder in male albino rats. Int. J. Med. Pl. Res., 5 (3): 209-220.

Nafees, S., S.T. Ahmed, W. Arjumand, N. Ali, S. Rashid and S. Sultana (2013). Hibiscus rosa sinensis alleviates thioacetamide induced Acute Hepatotoxicity in Wister Rats. Int. J. Drug Dev. and Res., 5 (1): 143-153.

Nidih, M., V.L. Tandon and A. Nunjal (2009). Evaluation of medicinal properties of Hibiscus rosa sinensis in male swiss albino mice. Int. J. Pharmaceutical and Clin. Res., 1 (3): 106-111.

Noda, Y., T. Kaneyuki, A. Mori and L. Packer (2002). Antioxidant activities of pomegranate fruit extract and its anthocyanidins: delphinidin, cyaniding, and pelargoidin. J. Agric. Food Chem., 2, 50 (1): 166.

Nozire, O. and D. Serpil (1993). Evaluation of the pomegranate (Punica granatum L.) peels from the stand point of pharmacy. Ankara Ecz. Fak. Derg., 22 (1-2): 21.

Nwibo, D.D., M.I. Eze and T.M. Okonkwo (2016). Effects of Hibiscus rosa-sinensis leaf products on heamatological induces, lipid profile and hepatic parameters of hyperlipidemic rat. Afr. J. Pharm. and Phamacol., (12): 223-229. 
Pengelly (2004). Triterpenoids and saponins. The constituents of medicinal plants (CABI Publishing, USA), 74.

Reitman, S. and S. Frankel (1957). A colorimetric method for the determination of serum glutamic oxalacetic and glutamic pyruvic transaminases. Ame. J. Clin. Pathol., 28: 56-63.

Saad, E.A., M.M. Hassanien, M.A. El-Hagrasy and K.H. Radwan (2015). Antidiabetic Hypolipidemic and antioxidant activities and protective effects of Punica granatum peels powder against pancreatic and hepatic tissues injuries in streptozotocin induced IDDM in rats. Int. J. Pharm. and Pharmaceutical Sci., 7 (7): 397-402.

Sastravaha, G., P. Yotnuengnit, P. Booncong and P. Sangtherapitikul (2003). Adhuntive periodontal treatment with Centella asiatica and Punica granatum extracts. Preliminary study. J. Int. Acad. Periodontol., 5(4): 106.

Satomi, H., K. Umemura, A. Ueno, T. Hatano, T. Okuda and T. Noro (1993). Carbonic anhydrase inhibitors from the pericarps of Punica granatum L. Biol Pharm. Bull., 16 (8): 787.

Satyavati, G.V., A.R. Gupta and N. Tandon, (1978). Medicinal Plants of India, Vol. 2. Indian Coun. Med. Res., New Delhi, 539.

Schmidt, M. and J. Eisenburg (1975). Serum bilirubin determination in newborn infants. A new micromethod for the determination of serum of plasma bilirubin in newborn infants. Fortschr. Med., 93: 1461-1466.

Schubert, S.Y., E.P. Lansky and I. Neeman (1999). Antioxidant and eicosanoid enzyme inhibition properties of pomegranate seed oil and fermented juice flavonoids. J. Ethnopharmacol., 66 (1): 11.
Sendecor, G.W. and W.C. Cochran (1969). In Statistical Methods. $6^{\text {th }}$ Ed. Iowa state Univ. press Ames, Iowa, USA, 70.

Singhal, K.C. (1983). Antihelmintic activity of Punica granatum and Artemesia siersiana against experimental infection in mice Ind. J. Pharmacol., 15: 119.

Van-Elswijk, D.A., U.P. Schobel, E.P. Lansky and G. Van-der-Greef (2004). Rapid dereplicaiton of estrogen compounds in Punica granatum using on-line biochemical detection coupled to mass spectrometry Photochem., 65 (2): 233.

Vasconcelos, L.C., M.C. Sampaio, F.C. Sampaio and J.S. Higino (2003). Use of punica granatum as an anti-fungal agent against candidosis associated with denture stomatitis. Mycoses; 46(5-6): 192.

Yazdanparast, R. and S. Bahramika (2006). Evaluation of the effect of Anethum graveolens $\mathrm{L}$ crude extracts on serum lipids and lipoproteins profiles in hypercholesterolaemic rats, DARU. 6: 88.

Yin, G., L. Gao, P. Xu, G. Jeney and M. Nakao (2011). Hepatoprotective and antioxidant effects of Hibiscus abdariffa extract against carbon tetrachloride-induce hepatocyte damage in Cyprinus carpino. In vitro Cello Dev. Biol. Anim., (47): 10-15.

Zaki, L.H., S.M. Mohamed, S.A. Bashandy, F.A. Morsy, K.M. Tawfik and A.A. Shahat, (2017). Hypoglycemic and antioxidant effects of Hibiscus rosa sinensis L. leaves extract on liver and kidney damage in streptozotecin induced diabetic rats, Afr. J. Pharm. and Pharmacol., 11(13): 161-169.

Zari, T.A. and A.M. Al-Attar (2011). Therapeutic effects of olive leaves extract on rats treated with a sublethal concentration of carbendazim, Europ. Rev. Med. and Pharmacol. Sci., 15 (4) : 413-426. 


\section{تقييم الدور الوقائي الكباي للمستخلصات المائية لأوراق نبات الهيكس روزا سينتسس وقثشور الرمان في الفئران البيضاء تلباء}

\section{محمود شكرى صنادق السيد}

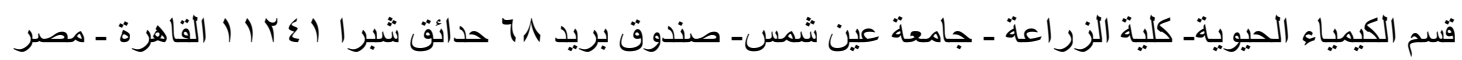

فى الدراسة الحالية ذهبت إلى التحقق من تأثيرات المستويات المختلفة منفردة ومجمعة للمنتجات الطبيعية (المستخلص

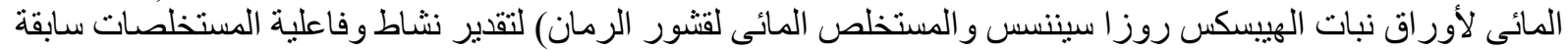

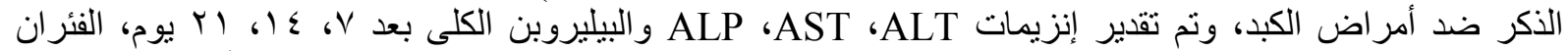

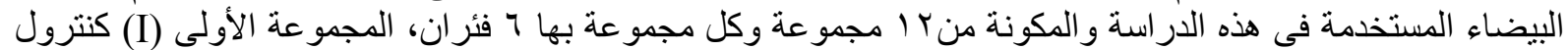

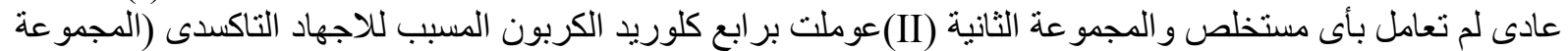

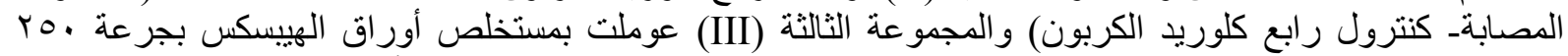

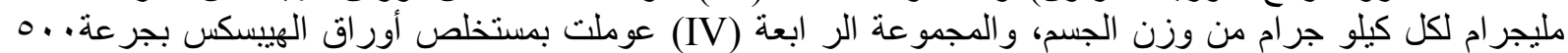

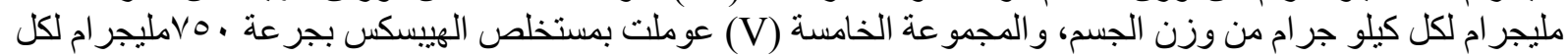

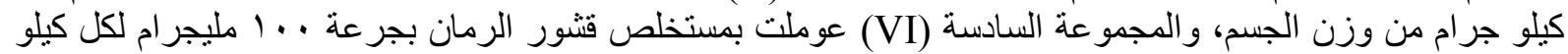

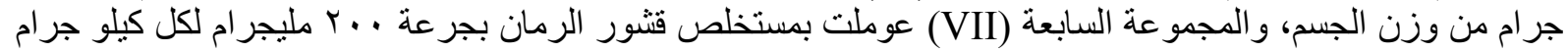

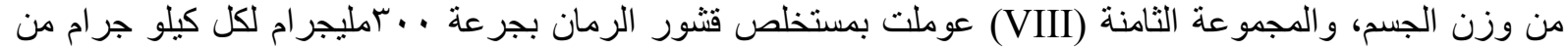

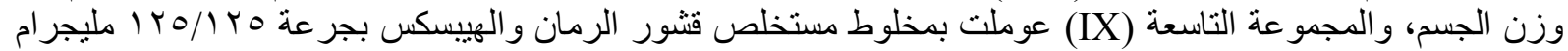

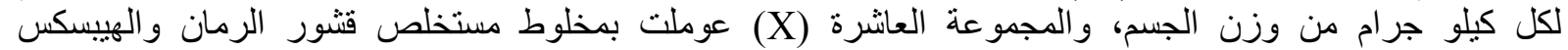

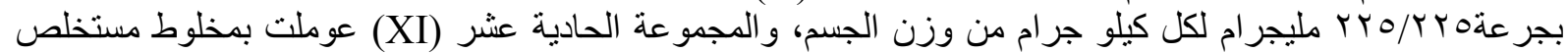

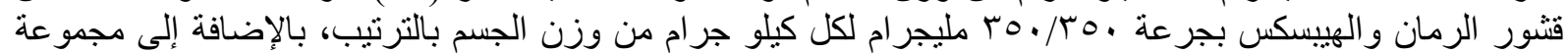

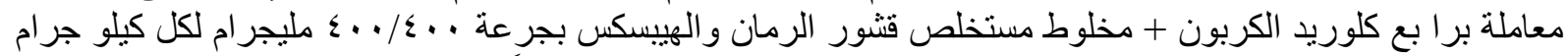

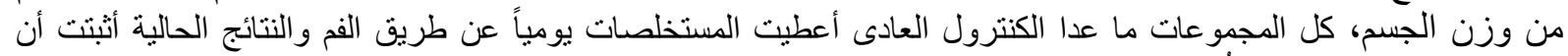

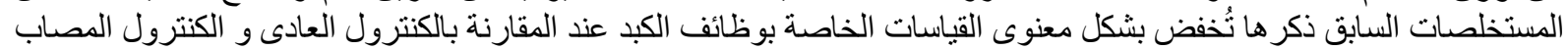
فى السيرم وبالنالى فهى لها دور وقائى تجاه النشاط الفسيولوجى للكبدا. 